\title{
Five Pearls for Long Eyes
}

\author{
Jonathan A Go, ${ }^{1}$ Akash Gupta ${ }^{1}$ and Sumitra S Khandelwal ${ }^{2}$ \\ 1. Baylor College of Medicine, Houston, TX, USA; 2. Cullen Eye Institute, Department of Ophthalmology, Baylor College of Medicine, \\ Houston, TX, USA
}

DOI: https://doi.org/10.17925/OPHT.2021.15.1.2

L ong eyes present unique challenges during cataract surgery. We provide five pearls for optimizing cataract surgery for these patients. The first is a complete preoperative examination, particularly looking for risk factors for retina complication following surgery. The second is to the refractive target with the patient, especially as many are near-sighted and may not understand that giving up near vision is the side effect of aiming for emmetropia with a monofocal lens. The third is to carefully evaluate of the biometry data and formulas available in these eyes, which can have unusual refractive results. Fourth is to plan for intraoperative surprises, including reverse pupillary block, deep anterior chamber and possible weak zonules that may require sizing of lenses and capsule tension rings for larger eyes. Finally, the fifth is to have a plan for the anisometropia between eyes. With these tips and careful counselling, patients can have excellent results after cataract surgery, despite having larger eyes.

\section{Keywords}

Long eyes, cataract surgery, refractive

Disclosure: Sumitra S Khandelwal is a consultant for Zeiss, Alcon, Bausch \& Lomb, Omidria, Ocular Therapeutix, and Dompe. Jonathan A Go and Akash Gupta have no financial or non-financial relationships or activities to declare in relation to this article.

Review process: Double-blind peer review.

Compliance with ethics: This study involves a review of the literature and did not involve any studies with human or animal subjects performed by any of the authors.

Authorship: The named authors meet the International Committee of Medical Journal Editors (ICMJE) criteria for authorship of this manuscript, take responsibility for the integrity of the work as a whole, and have given final approval for the version to be published.

Access: This article is freely accessible at touchOPHTHALMOLOGY.com (c) Touch Medical Media 2021

Received: 18 January 2021

Accepted: 27 April 2021

Published online: 12 July 2021

Citation: touchREVIEWS in Ophthalmology. 2021; 15(1):2-5

Corresponding author: Sumitra S Khandelwal, 1977 Butler Blvd, Houston, TX 77030, USA.

E: sumitra.khandelwal@bcm.edu

Support: No funding was received in

the publication of this article.
Primary myopia is a refraction anomaly of a non-accommodated eye with a spherical equivalent of -0.5 dioptres (D) or lower, often caused by an elongation of the visual axis. ${ }^{1}$ While visual axis length often varies between individuals and populations, a 'long eye' is often defined by an axial length greater than $24.5 \mathrm{~mm} .{ }^{2}$ The aberrant anatomy of long eyes, which includes longer axial lengths, larger sulcus spaces and larger white-to-white ratio, presents unique challenges for cataract surgery. We provide five pearls for optimizing cataract surgery for patients with long eyes (Table 1).

\section{Pearl 1: Complete a thorough preoperative exam}

Rhegmatogenous retinal detachment (RRD), the most common form of retinal detachment, is defined as a tear the retina which allows fluid to flow from the vitreous cavity into the subretinal space, creating retinal separation. ${ }^{3}$ Cataract surgery is an independent risk factor for RRD, due to the resulting accelerated liquefaction of the vitreous humor. ${ }^{4}$ Myopia, which is also associated with enhanced vitreous liquification, further compounds the risk of retinal detachment. ${ }^{5-8}$ Presence of a posterior vitreous detachment prior to cataract surgery can be protective for retinal detachment, although patients still have a higher risk. ${ }^{9}$ Studies have estimated an increased risk of $2.7-18.9 \mathrm{x}$ for pseudophakic myopes versus pseudophakic non-myopes. ${ }^{10}$ Thus, additional diligence is required when operating on long eyes.

We recommend the following precautions to mitigate the risk of RRD. First, a thorough preoperative examination of the lens and the retina should be performed. Specifically, peripheral examination and imaging, including topography and macular optical coherence tomography, should be completed when appropriate. Second, patients should be counselled and educated on the added operative risks associated with myopia. Finally, in patients at high risk for retina complications, a supplementary evaluation by a retina specialist should be considered, not only to rule out asymptomatic retinal tears or holes, but also to proactively connect the patient with a retina clinic that the patient can call for any future myopia-related retinal complications.

\section{Pearl 2: Discuss the target, again and again}

Patients with long eyes often require comprehensive counselling and education regarding the loss of near vision when given distance vision in both eyes. This trade-off may need to be reiterated with the patient several times to ensure understanding. Though these conversations may feel frustrating or circular, the surgeon is an invaluable guide for these patients and intentional, preoperative discussion is a necessity.

We suggest the following actions to enhance patient counselling. Firstly, consider asking patients to complete a pre-visit lifestyle questionnaire regarding their interests and priorities. This survey may prepare surgeons for patient expectations and streamline counselling conversations. Secondly, a patient should be counselled about loss of near vision with a monofocal lens aimed for distance. Key questions include: "do you take off your glasses to read at night?" Or: "do you take off your glasses to check your cell phone?" Emphasizing the loss of near vision is important for these 


\begin{tabular}{|c|c|}
\hline \multicolumn{2}{|l|}{ Five pearls for long eyes } \\
\hline Complete a thorough preoperative exam & $\begin{array}{l}\text { Mitigate the risk for retinal detachment by: } \\
\text { - Careful exam, topography and macula OCT } \\
\text { - Counselling myopes on heightened risk } \\
\text { - Evaluation by retina specialist }\end{array}$ \\
\hline Discuss the target, again and again & $\begin{array}{l}\text { Effectively counsel patients through: } \\
\text { - Pre-visit lifestyle questionnaire } \\
\text { - Emphasize the loss of near vision } \\
\text { Consider the risks and benefits of alternatives such as: } \\
\text { - Myopic target between -5.00D and -2.00D } \\
\text { - Multifocal or EDOF lenses }\end{array}$ \\
\hline Carefully decide on the lens power & $\begin{array}{l}\text { Adjust lens power calculations via: } \\
\text { - } \text { Modified vergence formulas, e.g. Wang-Koch }{ }^{17,18} \\
\text { - } \quad \text { Newer vergence formulas, e.g. Barrett II }\end{array}$ \\
\hline Have a plan for anisometropia & $\begin{array}{l}\text { Reduce risks for anisometropia by: } \\
\text { - Reducing time between eye surgeries } \\
\text { - Prescribing temporary corrective lenses/glasses } \\
\text { - Understand the risk and benefits of ISBCS }\end{array}$ \\
\hline
\end{tabular}

CTRS = capsular tension rings; EDOF = extended depth of fOCUS; IOL = intraocular lens; ISBCS = immediate sequential bilateral cataract surgery; OCT $=$ optical computed tomography.

activities. If the patient has a clear understanding, or a history of wearing contact lenses for distance with readers on top, bilateral emmetropia may be considered. If the patient is not accepting of loss of near vision, the surgeon can instead offer the option of keeping the patient myopic between $-5.00 \mathrm{D}$ to $-2.00 \mathrm{D}$ with prescribed reading glasses, if such a situation better aligns with the patient's preference. Monovision is a third option that can be offered, but is best tried prior to surgery or with a successful history of monovision in contact lenses.

Multifocal or extended depth of focus (EDOF) lenses can also be utilized. However, special consideration is required when evaluating premium lenses. In mild to moderate myopes, near-vision quality may be worse in multifocal lenses or EDOF lenses compared to pre-surgical near-vision quality with glasses removed. For patients who never remove their glasses to read, this trade-off is less concerning. These patients are usually higher myopes and could be good candidates. In addition, multifocal lenses may affect postoperative visual quality due to an amplified angle kappa. ${ }^{11}$ Finally, lens choice may complicate future retinal surgery, both from an imaging ${ }^{12}$ and an intraoperative visibility standpoint. ${ }^{13}$ Overall, these presbyopia-correcting lenses can be excellent for patients, but careful preoperative exam and counselling is important.

\section{Pearl 3: Carefully decide on the lens power}

Traditional vergence formulas assume a single global index of refraction for lens power calculations. However, eyes with a longer axial length will have a larger vitreous cavity; Thus, these formulas have the potential to underestimate lens power, leading to hyperopic surprise. In addition, techniques such as partial coherence interferometry, while more accurate than conventional ultrasound, assume the anterior chamber and axial length are proportional, which may also disrupt lens power calculations. ${ }^{14-16}$

We advise that surgeons adjust their lens power calculations, either by modifying traditional vergence formulas or employing newer formulas that account for varying axial length. Axial length modifications, such as the Wang-Koch adjustment to Holladay 1, have been proven to reduce hyperopic outcomes in myopic patients. ${ }^{17,18}$ These modified traditional formulas appear to be as accurate for myopes as newer-generation formulas, ${ }^{19}$ and may even be more accurate..$^{20}$

Alternatively, newer-generation formulas, which may better account for axial length variation, may also be utilized for myopes. Prior studies have reached differing conclusions regarding the best formula for long eyes. Previous analyses have suggested the SRK $/ T,{ }^{21}$ Barrett Universal $\|_{1}^{22-26}$ Haigis, ${ }^{27-29}$ Hill-RBF 2,30,31 or Olsen formulas are preferred. Some studies have shown head-to-head myopic performance between formulas can vary based on the specific characteristics of a given subgroup, ${ }^{32,33}$ and other studies have shown no significant myopic performance differences between formulas. ${ }^{34,35}$ However, a 2018 meta-analysis of 11 observational studies demonstrated the superiority of Barrett Universal ॥ over Holladay 2, SRK/T, Hoffer Q and Holladay 1 in predicting intraocular lens (IOL) power in long eyes. ${ }^{2}$ Newer formulas, such as Barrett and Kane, can offer improved outcomes in long eyes.22 In particular, the Kane formula has been shown to be superior to all the formulas described. ${ }^{36}$ In addition, intraoperative aberrometry can offer additional data to improve outcomes, although studies show modern formulas are similar in outcomes. ${ }^{37-40}$ 
Our clinic's best practices include utilizing a Barrett II and adjusted Holladay I. Surgeons may also consider operating on the non-dominant eye first with a slight myopic aim, then factoring in refractive predictive error from the first eye into their lens power calculations for the second eye.

\section{Pearl 4: Anticipate intraoperative surprises}

The risk of intraoperative complications may be enhanced in long eyes. For example, the risk of globe perforation from peribulbar and retrobulbar nerve blocks is elevated in eyes with greater axial length. ${ }^{41,42}$ When local anaesthesia is indicated, we advocate for topical anaesthesia or a subTenon's block, rather than a peribulbar or retrobulbar block. ${ }^{43}$

Reverse pupillary block is caused by increased anterior chamber pressure compared to posterior chamber pressure, which seals the iris posteriorly against the anterior lens capsule, creating a deeper anterior chamber. While reverse pupillary block can be caused by excessive pressure from irrigation during any cataract surgery, longer eyes may carry a higher risk due to their larger anterior chamber volume, which affects phacodynamics. In addition, posterior chamber volume is also increased, creating greater aqueous humour flow into the anterior chamber. ${ }^{44,45}$ When encountering reverse pupillary block, surgeons should carefully raise the iris with a blunt instrument to restore flow. Surgeons may also consider pre-emptively lowering their irrigation settings during the operation. The risk of tears in the posterior capsule of the lens is also increased in long eyes. ${ }^{46,47}$ In addition, high myopia can be a risk factor for zonular weakness. ${ }^{48}$ Thus, surgeons should complete phacoemulsification and irrigation/aspiration in myopes with particular caution, regardless of their experience level or tenure.

Finally, the anatomical irregularities of a long eye may impact surgical supplies. For example, anterior chamber lenses are sized based on the white-to-white corneal diameter, which is the horizontal distance between the borders of the corneal limbus, and capsule tension rings are based on estimated bag size, which is derived from estimated axial length. Because the white-to-white is increased in long eyes, ${ }^{49}$ capsule tension rings are not 'one size fits all', and the fit may be different than expected. Similarly, a larger white-to-white may allow dislocation of three-piece IOLs due to the IOL diameter lacking enough width to fill the haptic-to-haptic in larger eyes. We recommend capturing the optic in the anterior capsule to avoid movement in the sulcus space in the event that the IOL is not be safely implanted into the bag. Surgeons should be aware of these risks and plan their surgical supplies accordingly.

\section{Pearl 5: Have a plan for anisometropia}

In the time between surgery on a patient's first and second eye, anisometropia can be not only disconcerting, but also potentially dangerous for patients, due to an increased risk of falls. ${ }^{50}$ We propose the following solutions to help anticipate and curb the effects of anisometropia: First, surgeons should consider reducing the time between eye surgeries to reduce the period of anisometropia. Second, surgeons should consider placing a contact lens or prescribing temporary glasses until the second surgery is completed.

Immediate sequential bilateral cataract surgery (ISBCS) is commonly performed outside the United States, and its safety, efficacy and efficiency have been extensively studied. ${ }^{51,52}$ One benefit of ISBCS is the lack of an anisometropia period for patients. However, ISBCS, just like every other surgical technique, encompasses a unique portfolio of risks and benefits, which is outside the scope of this review. Nevertheless, surgeons should be cognizant of the range of options for addressing the temporary anisometropia between eyes.

\section{Conclusion}

In conclusion, long eyes present unique challenges for cataract surgeons. We provide five pearls for guidance surgeons to optimized surgical outcomes and patient satisfaction. $]$
De Jong PTVM. Myopia: Its historical contexts. Br J Ophthalmol. 2018; 102:1021-7.

2. Wang Q, Jiang W, Lin T, et al. Accuracy of intraocular lens power calculation formulas in long eyes: a systematic review and meta-analysis. Clin Exp Ophthalmol. 2018;46:738-49. Steel D. Retinal detachment. BMJ Clin Evid. 2014;2014:0710.

3. Steel D. Ret Wal detacher. BM Cln Evid. 2014,2014.0710. Feltgen N, Walter P. Rhegmatogenous retinal detachment-an Crim N, Esposito E, Monti R, et al. Myopia as a risk factor for subsequent retinal tears in the course of a symptomatic for subsequent retinal tears in the course of a symptomatic
posterior vitreous detachment. BMC Ophthalmol. 2017;17:1-5.

6. Haarman AEG, Enthoven CA, Tideman JWL, et al. The complications of myopia: A review and meta-analysis. Invest Ophthalmol Vis Sci. 2020;61:49.

7. Haug SJ, Bhisitkul RB. Risk factors for retinal detachment following cataract surgery. Curr Opin Ophthalmol. 2012;23:7-11. Lois N, Wong D. Pseudophakic retinal detachment. Surv Ophthalmol. 2003:48:467-87.

9. Ripandelli G, Coppé AM, Parisi V, et al. Posterior vitreous detachment and retinal detachment after cataract surgery. Ophthalmology . 2007;114(4):692-697. doi:10.1016/j. ophtha.2006.08.045.

10. Qureshi MH, Steel DHW. Retinal detachment following cataract phacoemulsification - a review of the literature. Eye. 2020;34:616-31

11. Fu Y, Kou J, Chen D, et al. Influence of angle kappa and angle alpha on visual quality after implantation of multifocal intraocular lenses. J Cataract Refract Surg. 2019;45:1258-64.

12. Dias-Santos A, Costa L, Lemos V, et al. The impact of multifocal intraocular lens in retinal imaging with optical coherence tomography. Int Ophthalmol. 2015;35:43-7.

13. Werner L, Wilbanks G, Nieuwendaal CP, et al. Localized opacification of hydrophilic acrylic intraocular lenses after procedures using intracameral injection of air or gas. J Cataract Refract Surg. 2015;41:199-207.

14. Gulkilik G, Ustuner A, Ozdamar A. Comparison of optical coherence biometry and applanation ultrasound biometry in high-myopic eyes with posterior pole staphyloma. Ann in high-myopic eyes with postric

15. Kolega MŠ, Kovačević S, čanović S, et al. Comparison of IOL-master and ultrasound biometry in preoperative intra ocular master and ultrasound biometry in preoperative intra ocul
lens (IOL) power calculation. Coll Antropol. 2015;39:233-5. lens (IOL) power calculation. Coll Antropol. 2015;39:233-5.
Fontes BM, Fontes BM, Castro E. Intraocular lens power

16. Fontes BM, Fontes BM, Castro E. Intraocular lens power
calculation by measuring axial length with partial optical coherence and ultrasonic biometry. Arq Bras Oftalmol. 2011;74:166-70

17. Wang L, Shirayama M, Ma XJ, et al. Optimizing intraocular lens power calculations in eyes with axial lengths above $25.0 \mathrm{~mm}$. J Cataract Refract Surg. 2011;37:2018-27.

18. Liu J, Wang L, Chai F, et al. Comparison of intraocular lens power calculation formulas in Chinese eyes with axial myopia. power calculation formulas in Chinese e
J Cataract Refract Surg. 2019;45:725-31.

19. Zhang $\perp$ Tan $X$. Wang W et al. Effect of axial length adjustment methods on intraocular lens power calculation in highly myopic eyes. Am J Ophthalmol. 2020;214:110-8.

20. Cheng H, Liu L, Sun A, Wu M. Accuracy of modified axial lengt adjustment for intraocular lens power calculation in Chinese axial myopic eyes. Curr Eye Res. 2020;45:827-33.

21. Aristodemou P, Knox Cartwright NE, Sparrow JM, Johnston RL. Formula choice: Hoffer Q, Holladay 1, or SRK/T and refractive outcomes in 8108 eyes after cataract surgery with biometn by partial coherence interferometry. J Cataract Refract Surg. 2011:37:63-71.

22. Kane JX, Van Heerden A, Atik A, Petsoglou C. Intraocular lens power formula accuracy: Comparison of 7 formulas. $J$ Cataract Refract Surg. 2016:42:1490-500.

23. Melles RB, Holladay IT, Chang WJ. Accuracy of intraocular lens calculation formulas. Ophthalmology. 2018;125:169-78.

24. Rong $\mathrm{X}, \mathrm{He}$ W, Zhu $\mathrm{Q}$, et al. Intraocular lens power calculation in eyes with extreme myopia: Comparison of Barrett Universal II, Haigis, and Olsen formulas. I Cataract Refract Surg. 2019;45:732-7

25. Ji J, Liu Y, Zhang J, et al. Comparison of six methods for the intraocular lens power calculation in high myopic eyes. Eur J Ophthalmol. 2021;31:96-102.

26. Zhou D, Sun Z, Deng G. Accuracy of the refractive prediction determined by intraocular lens power calculation formulas in high myopia. Indian J Ophthalmol. 2019;67:484-9.

27. Terzi E, Wang L, Kohnen T. Accuracy of modern intraocular lens power calculation formulas in refractive lens exchange for high myopia and high hyperopia. J Cataract Refract Surg. 2009:35:1181-9.

28. Roessler GE, Dietlein TS, Plange N, et al. Accuracy of intraocular lens power calculation using partial coherence interferometry in patients with high myopia. Ophthalmic Physiol Opt. 2012;32:228-33.

29. Bang $\mathrm{S}$, Edell $\mathrm{E}$, Yu Q, et al. Accuracy of intraocular lens calculations using the IOLMaster in eyes with long axial length and a comparison of various formulas. Ophthalmology 2011;118:503-6.

30. Wan KH, Lam TCH, Yu MCY, Chan TCY. Accuracy and precision of intraocular lens calculations using the new Hill-RBF version 2.0 in eyes with high axial myopia. Am J Ophthalmol. 2019:205:66-73.

31. Hill DC, Sudhakar S, Hill CS, et al. Intraoperative aberrometry versus preoperative biometry for intraocular lens power selection in axial myopia. I Cataract Refract surg. power selection
2017:43:505-10.

32. Cooke DL, Cooke TL. Comparison of 9 intraocular lens power calculation formulas. J Cataract Refract Surg. 2016;42:1157-6

33. Abulafia A, Barrett GD, Rotenberg M, et al. Intraocular lens power calculation for eyes with an axial length greater than $26.0 \mathrm{~mm}$ : Comparison of formulas and methods. I Cataract Refract Surg. 2015;41:548-56.

34. Roberts TV, Hodge C, Sutton G, Lawless M. Comparison of Hill-radial basis function, Barrett Universal and current third generation formulas for the calculation of intraocular lens power during cataract surgery Clin Exp Ophthalmol. 2018;46:240-6.

35. Srivannaboon S, Chirapapaisan C, Chirapapaisan N, et al. Accuracy of Holladay 2 formula using IOLMaster parameters in the absence of lens thickness value. Graefes Arch Clin Exp ophthalmol. 2013;251:2563-7.

36. Darcy K, Gunn D, Tavassoli S, et al. Assessment of the accuracy of new and updated intraocular lens power calculation formulas in 10930 eyes from the UK National Health Service. Cataract Refract Surg. 2020;46:2-7.

37. Solomon KD, Sandoval HP, Potvin R. Evaluating the relative value of intraoperative aberrometry versus current formulas for toric IOL sphere, cylinder, and orientation planning. J Cataract Refract Surg. 2019;45:1430e1435.

38. Solomon KD, Sandoval HP, Potvin R. Correcting astigmatism at the time of cataract surgery: toric IOLs and corneal relaxing incisions planned with an image-guidance system and intraoperative aberrometer versus manual planning and surgery. J Cataract Refract Surg. 2019;45:569-75.

39. Fisher B, Potvin R. Clinical outcomes with distance- dominant multifocal and monofocal intraocular lenses in post-LASIK cataract surgery planned using an intraoperative aberrometer. Clin Exp Ophthalmol. 2018;46:630-6.

40. Raufi N, James C, Kuo A, Vann R. Intraoperative aberrometry vs modern preoperative formulas in predicting intraocular lens 
power. J Cataract Refract Surg. 2020;46:857e861.

41. Fahmi A, Bowman R. Administering an eye anaesthetic: principles, techniques, and complications. Community Eye Health. 2008;21:14-7.

42. Palte HD. Ophthalmic regional blocks: management, challenges, and solutions. Local Reg Anesth. 2015;8:57-70.

43. Guay J, Sales K. Sub-Tenon's anaesthesia versus topica anaesthesia for cataract surgery. Cochrane Database Syst Rev. 2015;(8):CD00629

44. Itagaki H, Kunikata T, Hiratsuka K, et al. Reverse pupillary block associated with pigment dispersion syndrome after in-thebag intraocular lens implantation. J Cataract Refract Surg. 2013:39:1925-8.
45. Rhéaume MA, Duperré J, Harasymowycz P, Thompson P. Pigment dispersion and recurrent hyphema associated with in-the-bag lens implantation 1 Cataract Refract Surg. 2009:35:1464-7.

46. Fesharaki H, Peyman A, Rowshandel M, et al. A comparative study of complications of cataract surgery with phacoemulsification in eyes with high and normal axial length. Adv Blomed Res. 2012;1:67.

47. Zare M, Javadi MA, Einollahi B, et al. Risk factors for posterior capsule rupture and vitreous loss during phacoemulsification. J Ophthalmic Vis Res. 2014;4:208-12.

48. Ascaso FJ, Huerva V, Grzybowski A. Epidemiology, etiology, and prevention of late IOL-capsular bag complex dislocation: review of the literature. J Ophthalmol. 2015;2015:805706.

49. Hashemi H, Khabazkhoob M, Emamian MH, et al. White-todistribution in an adult population. J Curr Ophthalmol. 2015;27:21-4.

50. Yip JLY, Khawaja AP, Broadway D, et al. Visual acuity, selfreported vision and falls in the EPIC-Norfolk Eye study. Br J Ophthalmol. 2014;98:377-82.

51. Kessel L, Andresen J, Erngaard D, et al. Immediate sequential bilateral cataract surgery: a systematic review and metaanalysis. J Ophthalmol. 2015;2015:912481.

52. Arshinoff SA, Strube YN, Yagev R. Simultaneous bilateral cataract surgery. J Cataract Refract Surg. 2003;29:1281-91. doi:10.1155/2015/91248 